\title{
Chitosan promotes immune responses, ameliorating total mature white blood cell numbers, but increases glutamic oxaloacetic transaminase and glutamic pyruvic transaminase, and ameliorates lactate dehydrogenase levels in leukemia mice in vivo
}

\author{
MING-YANG YEH ${ }^{1 *}$, YUNG-LUEN SHIH ${ }^{2-4 *}$, HSUEH-YU CHUNG ${ }^{5}$, JASON CHOU $^{6}$, \\ HSU-FENG LU ${ }^{7}$, CHIA-HUI LIU ${ }^{8}$, JIA-YOU LIU ${ }^{7}$, WEN-WEN HUANG ${ }^{9}$, \\ SHU-FEN PENG ${ }^{9}$, LUNG-YUAN WU ${ }^{10^{*}}$ and JING-GUNG CHUNG ${ }^{9,11^{*}}$
}

${ }^{1}$ Office of Director, Cheng Hsin General Hospital, Taipei 112; ${ }^{2}$ Department of School of Medicine, Fu-Jen Catholic University, New Taipei 242; ${ }^{3}$ Department of Pathology and Laboratory Medicine, Shin Kong Wu Ho-Su Memorial Hospital, Taipei 111; ${ }^{4}$ School of Medical Laboratory Science and Biotechnology, Taipei Medical University, Taipei 110; ${ }^{5}$ Jen-Teh Junior College of Medicine, Nursing and Management, Miaoli County 356; Departments of ${ }^{6}$ Anatomical Pathology, ${ }^{7}$ Clinical Pathology, Cheng Hsin General Hospital, Taipei 112; ${ }^{8}$ The Center of General Education, Chia-Nan University of Pharmacy and Science, Tainan $717 ;{ }^{9}$ Department of Biological Science and Technology, China Medical University, Taichung 404; ${ }^{10}$ The School of Chinese Medicine for Post-Baccalaureate, I-Shou University, Kaohsiung 840; ${ }^{11}$ Department of Biotechnology, Asia University, Taichung 413, Taiwan, R.O.C.

Received May 10, 2016; Accepted May 5, 2017

DOI: $10.3892 / \mathrm{mmr} .2017 .6923$

\begin{abstract}
The aim of the present study was to investigate the effect of chitosan (a naturally derived polymer) on the immune responses and glutamic oxaloacetic transaminase (GOT), glutamic pyruvic transaminase (GPT) and lactate dehydrogenase (LDH) levels in WEHI-3 cell-generated leukemia mice. Mice were divided into control, WEHI-3 control, acetic acid (vehicle)-treated, and 5 and $20 \mathrm{mg} / \mathrm{kg}$ chitosan-treated groups. Mice were subsequently weighed, blood was collected, and liver and spleen samples were isolated and weighed. Blood samples were measured for cell markers, the spleen underwent phagocytosis and natural killer (NK) cell activity examination, and cell proliferation was analyzed by flow cytometry. Chitosan did not significantly affect the weights of body, liver and spleen at 5 and $20 \mathrm{mg} / \mathrm{kg}$ treatment. Chitosan increased
\end{abstract}

Correspondence to: Professor Jing-Gung Chung, Department of Biological Science and Technology, China Medical University, 91 Hsueh-Shih Road, Taichung 404, Taiwan, R.O.C.

E-mail: jgchung@mail.cmu.edu.tw

Dr Lung-Yuan $\mathrm{Wu}$, The School of Chinese Medicine for Post-Baccalaureate, I-Shou University, 8 Yida Road, Jiaosu Village, Yanchao, Kaohsiung 840, Taiwan, R.O.C.

E-mail: drwuly@gmail.com

${ }^{*}$ Contributed equally

Key words: chitosan, immune response, glutamic oxaloacetic transaminase, glutamic pyruvic transaminase, lactate dehydrogenase the percentage of CD3 ( $\mathrm{T}$ cells marker), decreased the levels of CD19 (B-cell marker) and CD11b at $5 \mathrm{mg} / \mathrm{kg}$ treatment, and decreased the levels of Mac-3 at 5 and $20 \mathrm{mg} / \mathrm{kg}$ treatment. Chitosan significantly increased macrophage phagocytosis of PBMCs, but did not significantly affect macrophage phagocytosis in the peritoneal cavity. Chitosan treatment did not significantly affect the cytotoxic activity of NK cells, and also did not affect $\mathrm{T}$ - and $\mathrm{B}$-cell proliferation. Chitosan significantly increased total white blood cell numbers, and GOT and GPT activities were both significantly increased. However, chitosan did not significantly affect LDH activity in leukemia mice. Chitosan may aid in future studies on improving immune responses in the treatment of leukemia.

\section{Introduction}

Leukemia, a group of cancers, are originated from blood-forming organs or tissues. A large number of immature and abnormal white blood cells (WBCs) are produced by the bone marrow, and those cells result in anemia and cause patients to be more susceptible to infection (1). Leukemia is the most common form of cancer in children worldwide (2). Leukemia can be divided into i) acute lymphocytic leukemia (ALL) derived from immature T or B lymphocytes; ii) acute myeloid leukemia (AML) from immature myeloid cells; iii) chronic lymphocytic leukemia (CLL) from mature B-lymphocytes; and iv) chronic myelogenous leukemia (CML) from granulocyte precursors $(3,4)$. In the USA, two most prevalent types of leukemia in children and adolescents are ALL and AML (5). In Western countries, CLL is the most common form of leukemia $(6,7)$. Currently, studies have fostered the 
development of novel drugs with different targets for leukemia patients. So far, the cure rate for leukemia is still unsatisfying and thus, treatments of leukemia remain a therapeutic challenge. The identification and development of novel agents from natural products to induce immune function is required.

Chitin ( $\beta$-(1-4)-poly- $N$-acetyl-D-glucosamine), a natural agent, is the major component of shell exoskeleton from shrimp and crabs $(8,9)$ and it can be converted to a deacetylate derivative termed chitosan, which is a linear heteropolysaccharide composed of $\alpha$-(1,4)-linked-D-glucosamine $(\mathrm{GlcN})$ and GlcNAc (10). The hydrolyzed products of chitosan, such as D-glucosamine oligomers [chitosan oligosaccharide (COS)] are soluble in water (11) and they have been demonstrated to have anti-bacterial, anti-tumor and anti-oxidant effects (12-14) and drug delivery functions (15). It was reported that COS possesses inhibitory effects on degranulation and cytokine generation in rat basophilic leukemia cells in vivo (16). Pretreatment with water-soluble chitosan in human astrocytoma cells can lead to inhibition of secretion and expression of the pro-inflammatory cytokines, tumor necrosis factor (TNF)- $\alpha$ and interleukin (IL)-6 (17).

Previous studies have demonstrated that chitosan can affect inflammation in vitro; however, limited information is available regarding how chitosan affects immune responses in vivo $(18,19)$. Therefore, in the present study, leukemia $\mathrm{BLAB} / \mathrm{c}$ mice were generated with WEHI-3 mouse leukemia cells, and the immune responses were subsequently evaluated in vivo. Glutamic oxaloacetic transaminase (GOT), glutamic pyruvic transaminase (GPT) and lactate dehydrogenase (LDH) levels in mice following oral administration of chitosan were measured. The results indicated that chitosan increased levels of the cell markers cluster of differentiation (CD) 3, CD11b, CD19 and Mac-3, increased macrophage phagocytosis and natural killer (NK) cell activity, and affected GOT, GPT and $\mathrm{LDH}$ levels in leukemia BALB/c mice in vivo.

\section{Materials and methods}

Materials and reagents. Acetic acid, concanavalin A (Con A), dimethyl sulfoxide (DMSO), lipopolysaccharide (LPS) and YAC-1 cells were purchased from Sigma-Aldrich; Merck KGaA (Darmstadt, Germany). RPMI-1640 medium, fetal bovine serum (FBS), L-glutamine and antibiotics (penicillin-streptomycin) were purchased from Gibco; Thermo Fisher Scientific, Inc. (Waltham, MA, USA). Antibodies against CD3, CD19, CD11b and Mac-3 were obtained from BD Biosciences (San Jose, CA, USA). Chitosan powder with molecular weight of $\sim 86,000 \mathrm{kDa}$ (Koyo Chemical Co., Ltd, Osaka, Japan) was obtained from the National Taiwan University College of Medicine Animal Medicine Center (Taipei, Taiwan, Republic of China). It was dissolved in acetic acid, and 5 and $20 \mathrm{mg} / \mathrm{kg}$ solutions were separately suspended in $0.2 \mathrm{ml}$ acetic acid at room temperature for $1 \mathrm{~h}$ before use (20).

WEHI-3 cells. The WEHI-3 murine acute myelomonocytic leukemia cell line was purchased from the Food Industry Research and Development Institute (Hsinchu, Taiwan, Republic of China). Cells were cultured in $75 \mathrm{~cm}^{2}$ tissue culture flasks containing RPMI 1640 medium supplemented with 10\% FBS, 2 mM L-glutamine and antibiotics (100 U/ml penicillin and $100 \mu \mathrm{g} / \mathrm{ml}$ streptomycin) and placed in a humidified atmosphere of $5 \% \mathrm{CO}_{2}$ at $37^{\circ} \mathrm{C}(21)$. Cells were allowed to re-equilibrate for $24 \mathrm{~h}$ prior to use.

Male BALB/c mice. Male BALB/c mice (age, 8 weeks; weight, 22-25 g; n=50) were obtained from the National Laboratory Animal Center (Taipei, Taiwan, Republic of China). Mice were maintained in stainless steel mesh-bottomed cages with specified pathogen-free conditions in the animal center of China Medical University (Taichung, Taiwan, Republic of China) as in a previous study (22). All animals procedures were carried out following the institutional guidelines for animal welfare of China Medical University and were firstly approved by the Institutional Animal Care and Use Committee of China Medical University as described previously (21).

Treatment of animals with chitosan. BLAB/c mice were randomly separated into five groups ( $n=10 /$ group). Group I were normal animals. Groups II-V were peritoneally injected with $1 \times 10^{6}$ WEHI-3 leukemia cells. Groups I and II received a normal diet as a control. Group III mice received a normal diet with acetic acid administered by oral gavage. Group IV mice received chitosan $(5 \mathrm{mg} / \mathrm{kg})$ in acetic acid (vehicle). Group V mice received chitosan $(20 \mathrm{mg} / \mathrm{kg})$ in acetic acid. Chitosan dissolved in acetic acid was administered by oral gavage individually to each mouse in groups IV and $\mathrm{V}$ every 2 days for 15 days. All mice from each group were individual weighed during the oral treatment and after treatment, and all mice were weighed and sacrificed by euthanasia with $\mathrm{CO}_{2}$ as described previously (21).

Immunofluorescence staining for leukocytes surface markers. After treatment, all mice were weighed, blood were collected by cardiocentesis under general anesthesia using a disposable syringe with needle (20-gauge), and liver and spleens were dissected and weighed (23). Collected blood (1 ml/mouse) was lysed with 1X Pharm Lyse ${ }^{\mathrm{TM}}$ lysing buffer (BD Biosciences) to destroy red blood cells and leukocytes, as described previously (21). Following centrifugation at $1,500 \mathrm{x}$ g for $15 \mathrm{~min}$ at $4^{\circ} \mathrm{C}$, white blood cells were collected and stained with phycoerythrin (PE)-labeled anti-mouse CD3 (BD553062; BD Biosciences, San Jose, CA, USA), PE-labeled anti-mouse CD19 (BD553786; BD Biosciences), fluorescein isothiocyanate (FITC)-labeled anti-mouse CD11b (BD553310; BD Biosciences) and FITC-labeled anti-mouse Mac-3 (BD553324; BD Biosciences) antibodies at 1:12 dilution of each for $30 \mathrm{~min}$ at $4{ }^{\circ} \mathrm{C}$. All samples were analyzed by flow cytometry (BD Biosciences) and quantified using CellQuest software version 5.2.1 (BD Biosciences), as previously described (21).

Measurements of macrophage phagocytosis. Macrophages were isolated from peripheral blood mononuclear cells (PBMCs) and the peritoneum of each mouse per group, as described previously (21). Macrophages were added to plates which contained $50 \mu 1$ target E. coli-FITC, and mixed according to the PHAGOTEST ${ }^{\circledR}$ kit manufacturer's protocol (ORPEGEN Pharma GmbH, Heidelberg, Germany). Samples were then analyzed for phagocytosis using flow cytometry. Phagocytosis was quantified using CellQuest software version 5.2.1 (BD Biosciences), as previously described (21). 


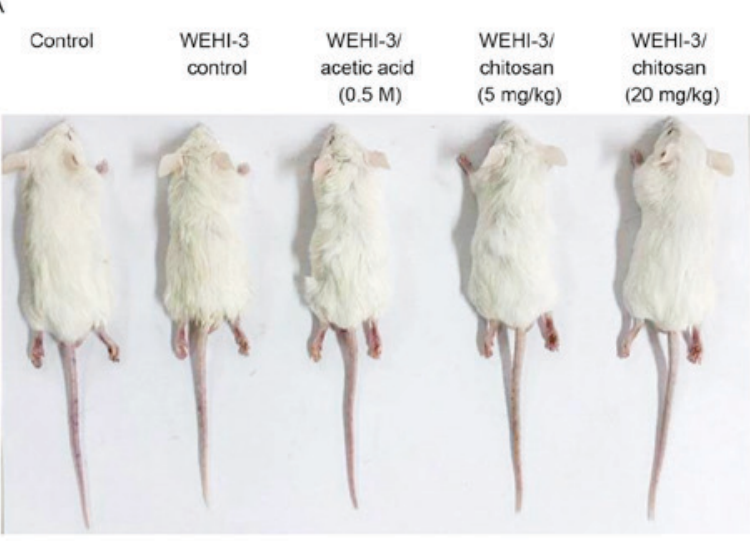

C

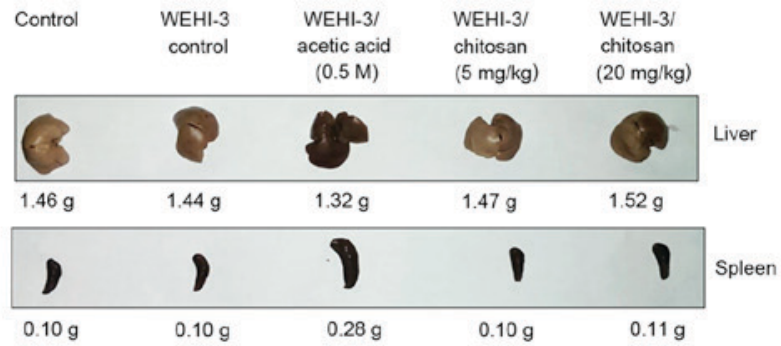

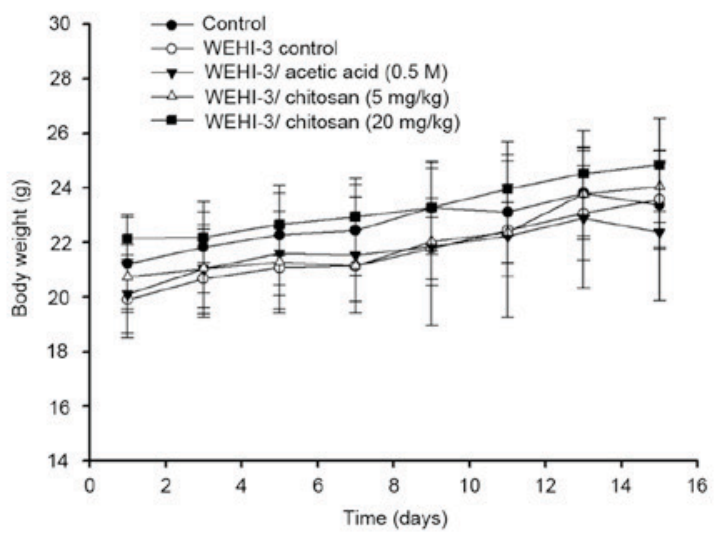

D

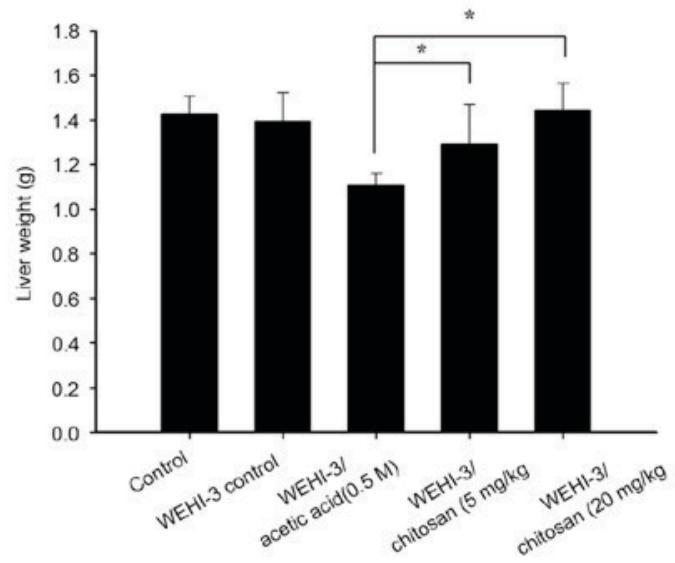

$\mathrm{E}$

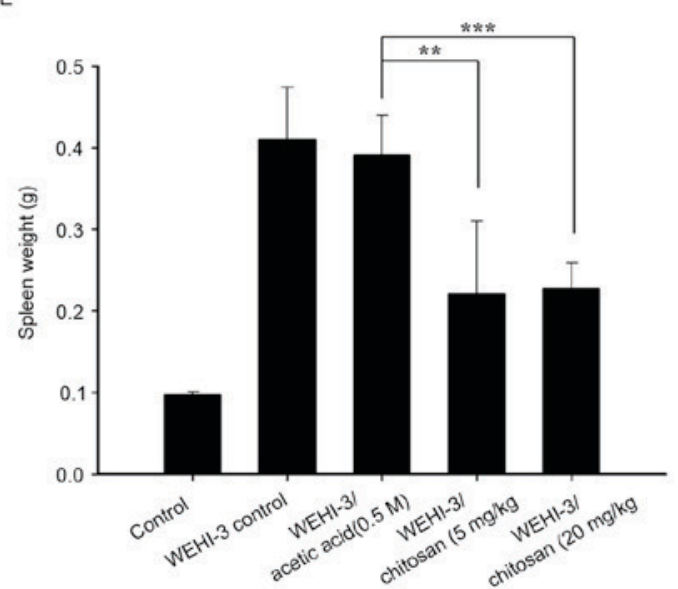

Figure 1. Effects of chitosan on the appearance, and body, liver and spleen weights of WEHI-3 cell generated leukemia BALB/c mice. (A) Appearance of mice. (B) Body weight. (C) Images of livers and spleens. (D) Liver and (E) spleen weights. Data are expressed as the mean \pm standard deviation of three independent experiments ( $\mathrm{n}=10 /$ group). ${ }^{*} \mathrm{P}<0.05,{ }^{* * *} \mathrm{P}<0.01,{ }^{* * * *} \mathrm{P}<0.001$.

Measurements of NK cell cytotoxic activity. Splenocytes were isolated from each spleen per mouse as described previously (21). Splenocytes ( $1 \times 10^{5}$ cells/well) were seeded into a 96-well plate containing $1 \mathrm{ml}$ RPMI-1640 medium. The target YAC-1 cells $\left(2.5 \times 10^{7}\right.$ cells $)$ in $15 \mathrm{ml}$ tubes and PKH-67/Dil.C buffer (Sigma-Aldrich; Merck KGaA) was added to cells in tubes according to the manufacturer' protocol, and were mixed thoroughly for $2 \mathrm{~min}$ at $25^{\circ} \mathrm{C}$. PBS $(2 \mathrm{ml})$ was added to tube for $1 \mathrm{~min}$, and $4 \mathrm{ml}$ medium was also added to the tube and were centrifuged at $290 \mathrm{x} \mathrm{g}$ for $2 \mathrm{~min}$ at $25^{\circ} \mathrm{C}$. Approximately $2.5 \times 10^{6}$ YAC- 1 cells in $100 \mu \mathrm{l}$ in serum-free RPMI-1640 medium were seeded into 96 -well plates containing splenocytes $\left(1 \times 10^{5}\right.$ cells/well $)$ for $12 \mathrm{~h}$ at $37^{\circ} \mathrm{C}$. After incubation, NK cell cytotoxic activity was measured by flow cytometry as described previously (21).

Measurements of $T$ and $B$ cell proliferation. Isolated splenocytes from each mouse were suspended in PBS 
A

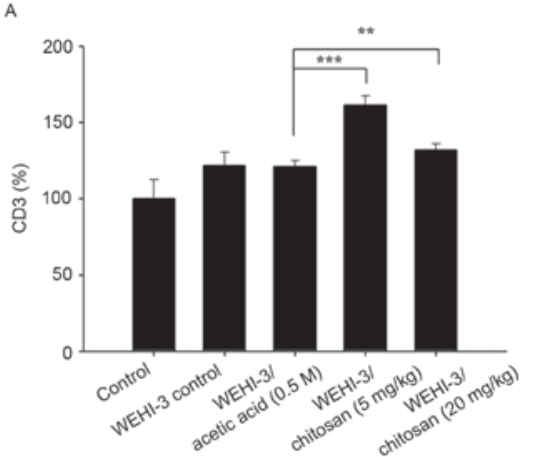

c

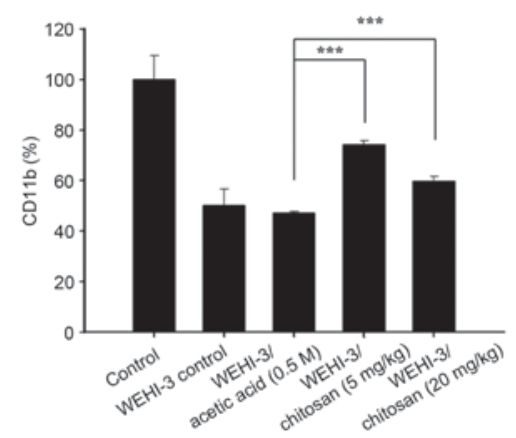

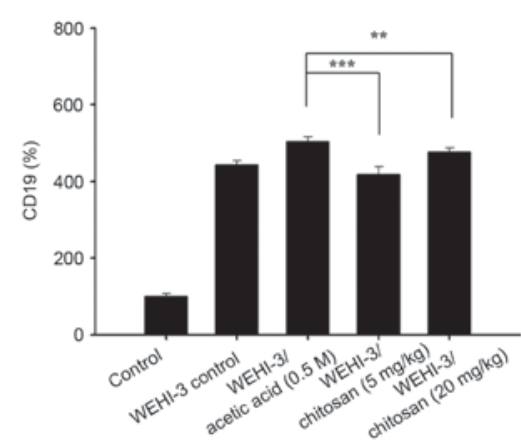

D

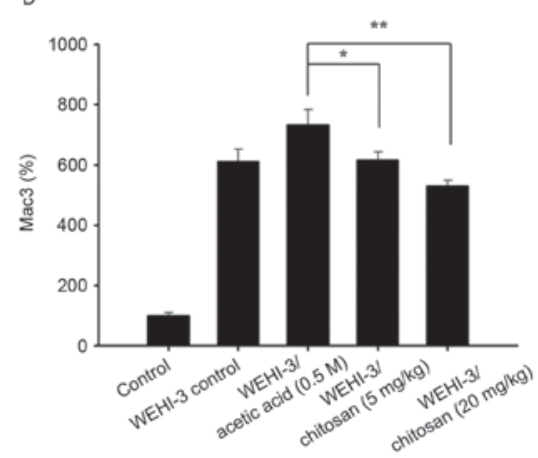

Figure 2. Effects of chitosan on levels of cell markers in white blood cells from leukemia BALB/c mice. Blood was collected from all mice and was analyzed for (A) CD3, (B) CD19, (C) CD11b and (D) Mac3 levels by flow cytometry. Data are expressed as the mean \pm standard deviation of three independent experiments ( $\mathrm{n}=10$ /group). ${ }^{*} \mathrm{P}<0.05,{ }^{* *} \mathrm{P}<0.01,{ }^{* * *} \mathrm{P}<0.001$. $\mathrm{CD}$, cluster of differentiation.

and seeded into 96 -well plates $\left(100 \mu 1 ; 1 \times 10^{5}\right.$ cells/well $)$ containing $100 \mu \mathrm{l}$ RPMI-1640 medium. To measure T-cell proliferation, $0.5 \mu \mathrm{g} / \mathrm{ml}$ Con A was added to the cells to stimulate for 3 days. For B cell proliferation, $1 \mu \mathrm{g} / \mathrm{ml}$ LPS was added to the cells to stimulate for 5 days. At the end of stimulation, cell proliferation was measured using a CellTiter 96 AQueous One Solution Cell Proliferation Assay kit (Promega Corporation, Madison, WI, USA) as previously described (21).

Measurement of white blood cells (WBCs), and GOT, GPT and $L D H$ levels of leukemia BALB/c mice after exposure to chitosan. All blood samples were collected from each mouse per group. Total WBCs were measured using flow cytometry. The levels of GOT and GTP were measured using liquiUV tests (aspartate aminotransferase and alanine aminotransferase, respectively), and LDH levels were also measured using a liquiUV test (Human Gesellschaft fur Biochemica und Diagnosica mbH, Wiesbaden, Germany), as described previously $(24,25)$.

Statistical analysis. Data are expressed as the mean \pm standard deviation from three independent experiments. Statistical comparisons between chitosan-treated and un-treated (control) groups were analyzed by Student's t-test. $\mathrm{P}<0.05$ was considered to indicate a statistically significant difference.

\section{Results}

Chitosan affects the weights of body, liver and spleen in leukemia $B A L B / c$ mice. WEHI-3 cells generated leukemia mice that were divided into 4 experimental groups: One positive control, one treated with acetic acid (vehicle) and the other two treated with chitosan at 5 and $20 \mathrm{mg} / \mathrm{kg}$ per 2 days for 15 days (total 7 times). Control mice (group I) were treated with a normal diet. The representative animals, body weights, liver and spleen weights are presented in Fig. 1, respectively. These results indicated that chitosan did not significantly affect the body weights and spleen weights of the animals, but it significantly increased liver weights when compared with the vehicle (acetic acid) treated group (Fig. 1D).

Chitosan affects cells markers of WBCs in leukemia BALB/C mice. After animals were divided into 5 groups and were treated with or without chitosan, blood samples were collected from each mouse per group. The levels of cell markers CD3, CD19, CD11b and Mac-3 from isolated cells were measured and the results are presented in Fig. 2, respectively. The results indicated that chitosan promoted CD3 (Fig. 2A) and CD19 (Fig. 2B) at both dose of treatment, compared with acetic acid treatment only. However, chitosan decreased the levels of CD11b at $5 \mathrm{mg} / \mathrm{kg}$ (Fig. 2C) and decreased the levels of Mac-3 at both doses (Fig. 2D) compared with the acetic acid-treated groups.

Chitosan affects macrophage phagocytosis in PBMCs and the peritoneal cavity of leukemia BALB/c mice. After treatment, cells were isolated from PBMCs and the peritoneal cavity of each animal, and the percentage of macrophages phagocytosis was measured. Chitosan treatment at both doses ( 5 and $20 \mathrm{mg} / \mathrm{kg}$ ) to leukemia mice did not significantly induce macrophage phagocytosis in the peritoneal cavity (Fig. 3A), but significantly increased it in PBMCs at both doses of treatment (Fig. 3B). 
A

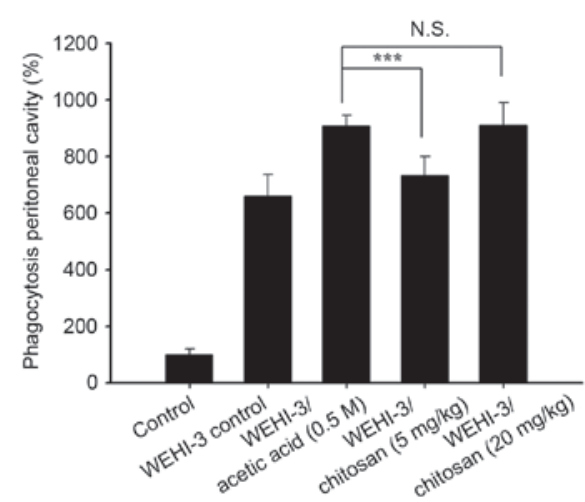

B

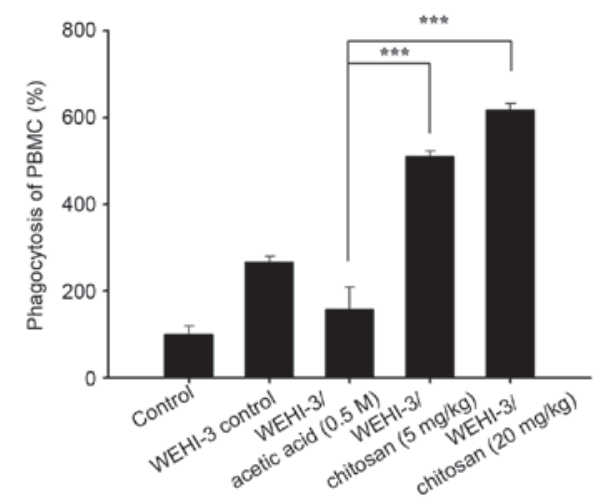

Figure 3. Effects of chitosan on macrophage phagocytosis from PBMCs and the peritoneal cavity of leukemia BALB/c mice. Blood samples were collected from mice then macrophages were isolated from (A) the peritoneal cavity and (B) PBMCs. Phagocytosis of macrophages was analyzed by flow cytometry. Data are expressed as the mean \pm standard deviation of three independent experiments ( $\mathrm{n}=10$ /group). ${ }^{* * *} \mathrm{P}<0.001$. N.S., nonsignificant; PBMCs, peripheral blood mononuclear cells.

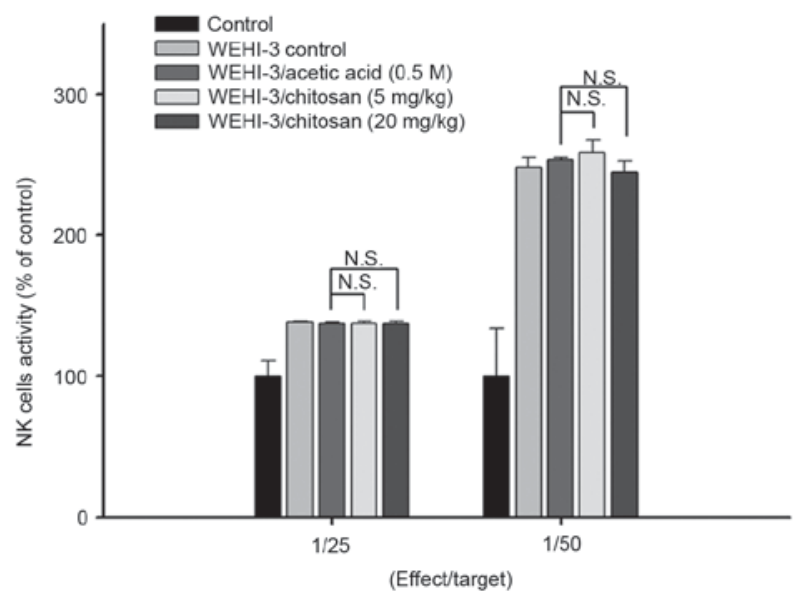

Figure 4. Effects of chitosan on the cytotoxic activity of NK cells in leukemia $\mathrm{BALB} / \mathrm{c}$ mice. NK cell cytotoxic activity was measured by flow cytometry. Data are expressed as the mean \pm standard deviation of three independent experiments ( $n=10 /$ group). N.S., nonsignificant; NK, natural killer.

Chitosan affects the cytotoxic activity of NK cells in leukemia $B A L B / c$ mice. YAC-1 cells were selected as targets for NK cells isolated from splenocytes, and the activities of NK cells were assayed by flow cytometry. The results indicated that chitosan did not significantly affect NK cells cytotoxic activity

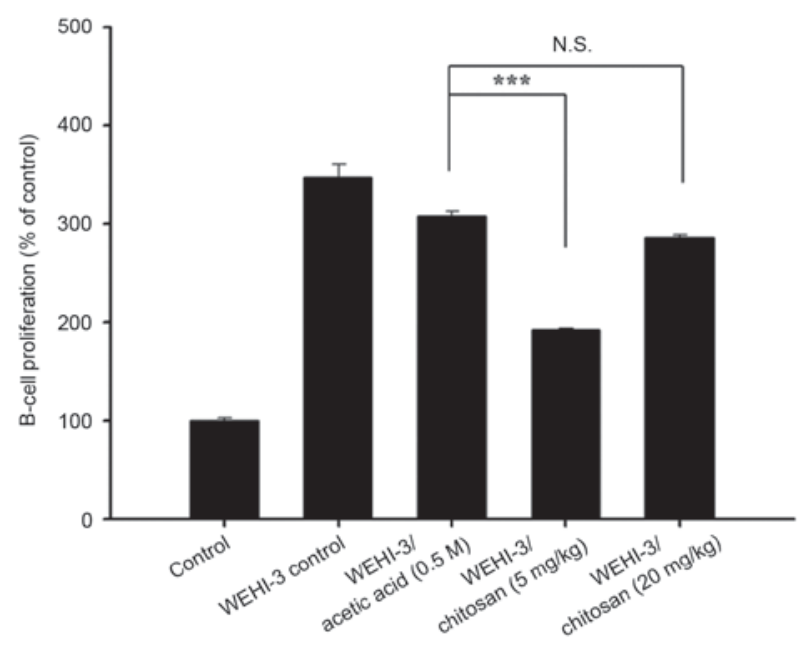

B

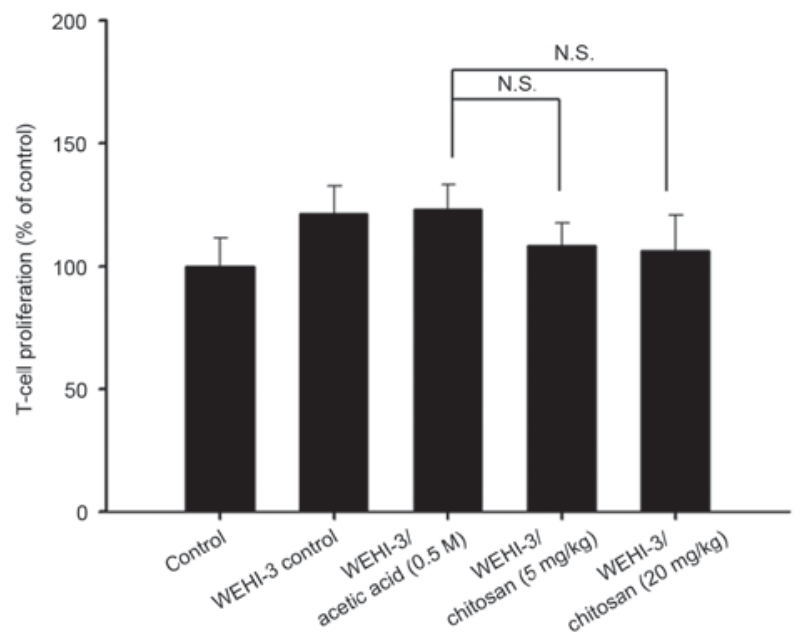

Figure 5. Effects of chitosan on $\mathrm{T}$ and $\mathrm{B}$ cell proliferation in leukemia $\mathrm{BALB} / \mathrm{c}$ mice. Isolated $\mathrm{T}$ and $\mathrm{B}$ cells were pretreated with concanavalin $\mathrm{A}$ and lipopolysaccharide to assess (A) B and (B) T cell proliferation, respectively, and the results were analyzed by flow cytometry. Data are expressed as the mean \pm standard deviation of three independent experiments ( $n=10 /$ group). ${ }^{* * *} \mathrm{P}<0.001$. N.S., nonsignificant.

at both doses of treatment when compared with acetic acid treated groups (Fig. 4).

Chitosan affects $T$ and $B$ cell proliferation in leukemia $B A L B / C$ mice. Splenocytes were isolated from each mouse per group after treatment with or without chitosan, and were assessed by flow cytometry for T- and B-cell proliferation after stimulating with Con A or LPS, respectively. The lower dose of chitosan reduced B-cell proliferation (Fig. 5A); however, neither dose had any effect on T-cell proliferation compared with the acetic acid treated group (Fig. 5B).

Chitosan affects WBC number, and the activity of GOT, GPT and $L D H$ in leukemia $B A L B / c$ mice. Blood samples were individually collected from animals of each group. Chitosan 
A

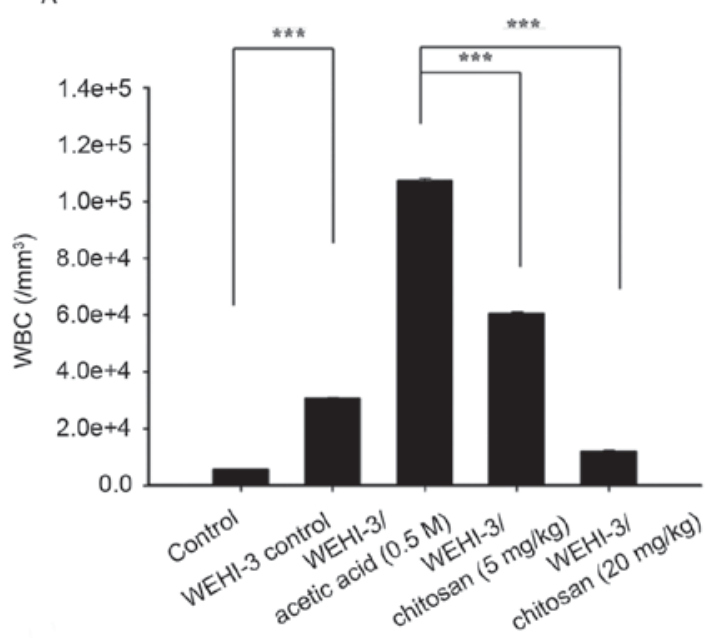

C

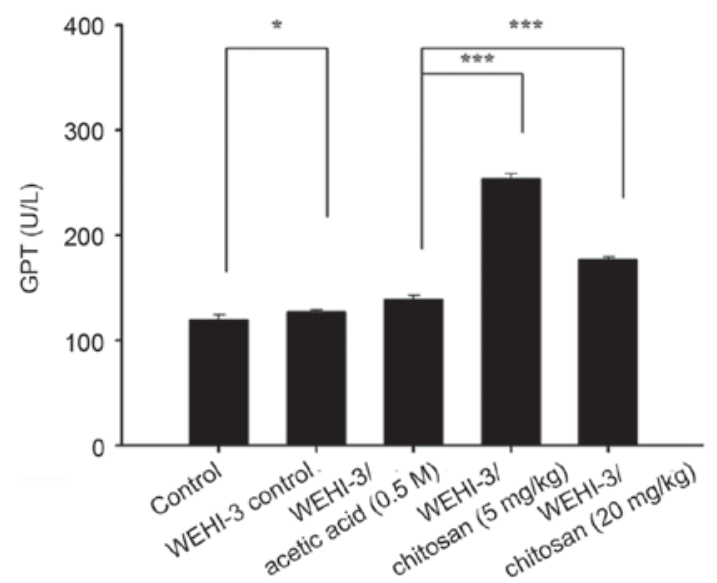

B

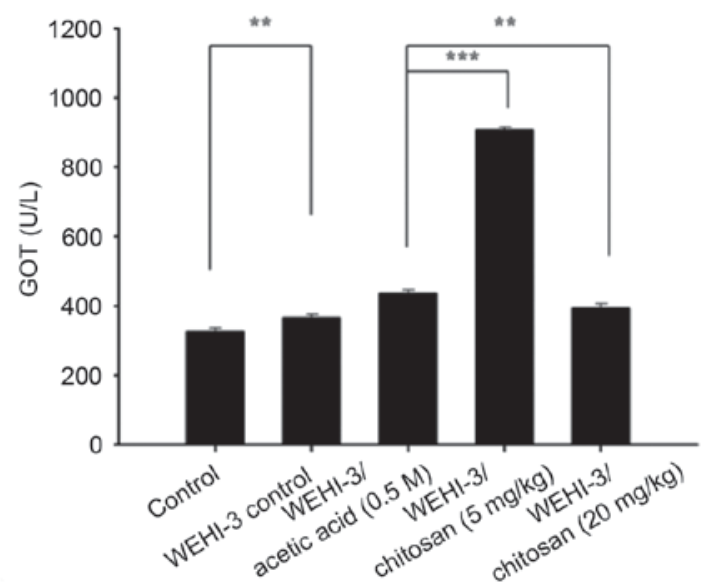

D

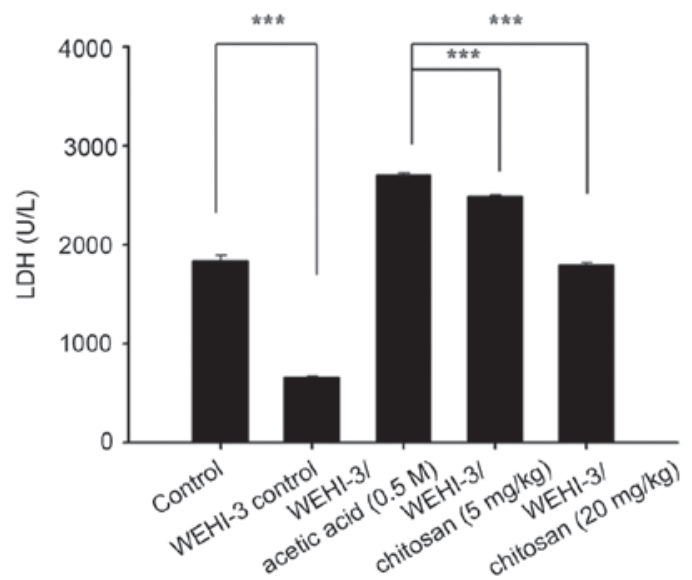

Figure 6. Measurement of total WBCs, GOT, GPT and LDH activity of leukemia BALB/c mice after exposure to chitosan. (A) WBC numbers, and (B) GOT, (C) GPT and (D) LDH levels. Data are expressed as the mean \pm standard deviation of three independent experiments ( $=10 /$ group). ${ }^{*}<0.05$, ${ }^{* *} \mathrm{P}<0.01,{ }^{* * *} \mathrm{P}<0.001$. GOT, glutamic oxaloacetic transaminase; LDH, lactate dehydrogenase; GPT, glutamic pyruvic transaminase; WBC, white blood cell.

at both doses of treatment significantly decreased total WBC numbers compared with the acetic acid group; however, $20 \mathrm{mg} / \mathrm{kg}$ chitosan resulted in a greater decrease in cell numbers compared with $5 \mathrm{mg} / \mathrm{kg}$ (Fig. 6A). There was a similar trend in GOT (Fig. 6B) and GPT (Fig. 6C) activity-both doses significantly increased their activities, and the greatest effect was observed at $5 \mathrm{mg} / \mathrm{kg}$. High doses of chitosan induced lower LDH activities compared with low dose treatment (Fig. 6D). Both doses of chitosan treatment were reduced compared with acetic acid treatment only.

\section{Discussion}

Previous studies have demonstrated that the hydrolyzed products of chitosan (chitosan oligosaccharide) have biological activities, but the majority of these studies are in vitro or treated in animals via intravenous or intraperitoneal administration (26-28). In our primary studies, chitosan was demonstrated to have hypolipidemic effects which partly involved the suppression of intestinal lipid absorption and hepatic acyl coenzyme A:cholesterol acyltransferase-2 expression (29), and chitosan slowed down the rate of tumor growth; however, it did not inhibit tumor formation (29). So far, there is no available information on if chitosan affects immune responses in leukemia mice. Therefore, in the present study, WEHI-3 mouse leukemia cells were used to generate murine leukemia in BALB/c mice, and mice were then randomly divided into 4 groups, including mice with a normal diet, and others treated with acetic acid (vehicle) or oral treatment of chitosan at 5 and $20 \mathrm{mg} / \mathrm{kg}$. Each animal was weighed throughout treatment. All blood samples and liver and spleen tissues were collected under anesthesia for further measuring levels of CD cell markers, macrophage phagocytosis, NK cell activities and $\mathrm{T}$ and $\mathrm{B}$ cell proliferation. Blood samples also measured the total WBC number, and the activity of blood GOT, GPT and LDH.

These results indicated that chitosan did not significantly affect the body weights and spleen weights of the animals. Liver weights, however, were affected. After assessing cell markers, it was demonstrated that chitosan increased the population of surface markers such as CD3 and CD19, but decreased the levels of CD11b at the $5 \mathrm{mg} / \mathrm{kg}$ dose level, and decreased the levels of Mac-3 at both doses. These observations indicated that chitosan may affect cell populations, such as $\mathrm{T}$ and $\mathrm{B}$ cells, and monocytes and macrophages. Therefore, the present study also examined $\mathrm{T}$ and $\mathrm{B}$ cell proliferation after stimulation with Con A or LPS, respectively, from isolated 
splenocytes from each group of mice. The results indicated that chitosan at 5 and $20 \mathrm{mg} / \mathrm{kg}$ did not significantly affect T-cell proliferation; however, at low doses of treatment, decreased B-cell proliferation. Furthermore, chitosan treatment at both doses significantly decreased WBC numbers compared to acetic acid treatment only. In human immune responses for against invading foreign antigens, $\mathrm{T}$ and $\mathrm{B}$ cells, monocytes and macrophages serve critical roles, and macrophages are responsible for phagocytosis to destroy antigens (30), and serve important roles in innate immunity $(31,32)$. Thus, it is well known that agents increase immune responses, and one hallmark is increased macrophage phagocytosis.

After treatment of each group mice, cells were isolated from PBMCs and the peritoneal cavity of each animal, and macrophage phagocytosis was subsequently measured. Chitosan treatment at 5 and $20 \mathrm{mg} / \mathrm{kg}$ significantly increased macrophage phagocytosis, but did not significantly affect macrophage phagocytosis in the peritoneal cavity. It was reported that macrophage lineage is heterogeneous (33), and the location and inflammatory environment can affect their function and activation (34). Chitosan downregulates expression of pro-inflammatory markers (CD86 and major histocompatibility complex II) from macrophages, decreases pro-inflammatory cytokines (TNF- $\alpha$ ), but increases anti-inflammatory cytokines (IL-10 and transforming growth factor- $\beta 1)(35,36)$. Chitosan may be useful in the prevention or treatment of periodontal inflammation (37). NK cells also serve an important role in innate immunity especially during the early phase of immune responses against certain viruses, parasites and microbial pathogens (38). The results of the present study indicated that chitosan did not significantly affect NK cells cytotoxic activity at both doses of treatment, when compared with acetic acid treated groups. Therefore, further investigations are required to confirm associated immune responses from chitosan.

The levels of GOT, GTP and LDH were measured from blood sample of each animal from each group, and the results indicated that chitosan at 5 and $20 \mathrm{mg} / \mathrm{kg}$ treatment significantly increased GOT and GPT levels; however, $5 \mathrm{mg} / \mathrm{kg}$ increased higher levels than $20 \mathrm{mg} / \mathrm{kg}$ treatment. In serum, high levels of GPT and GOT which reflect the developments of hepatic cell destruction are closely associated with hepatitis (39). Both doses of chitosan did not significantly increase the levels of LDH activities, which were lower than acetic acid-treated mice only. In patients with abdominal trauma, abnormal hepatic transaminase and LDH levels are associated with liver injury (10). The degrees of deacetylation, molecular weight, viscosity, and $\mathrm{pKa}$ may be involved in the great variability observed in chitosan treatment (10). Thus, further investigations are required in the future.

In conclusion, the present study demonstrated that chitosan modulates immune responses, potentially via $\mathrm{T}$ and $\mathrm{B}$ cell populations and increase of macrophage phagocytosis in the blood that may offer evidence for the function of chitosan in leukemia patients in the future.

\section{Acknowledgements}

The present study was supported by Cheng Hsin General Hospital (grant no 104-01) and Shin Kong Wu Ho-Su Memorial Hospital (grant no SKH-8302-103-NDR-0).

\section{References}

1. Bennett JM, Catovsky D, Daniel MT, Flandrin G, Galton DA, Gralnick HR and Sultan C: Proposals for the classification of the acute leukaemias. French-American-British (FAB) co-operative group. Br J Haematol 33: 451-458, 1976.

2. American Cancer Society: Global Cancer Facts \& Figures. 3rd edition. American Cancer Society, 2015.

3. Bain BJ: Acute leukemia cytology, cytochemistry and the FAB classification. In: Leukemia Diagnosis. Blackwell Science, Oxford, UK, pp1-52, 1999.

4. Bray F, Jemal A, Grey N, Ferlay J and Forman D: Global cancer transitions according to the human development index (2008-2030): A population-based study. Lancet Oncol 13: 790-801, 2012.

5. American Cancer Society: Cancer Facts \& Figures 201s. 2014. American Cancer Society, 2014.

6. Morton LM, Wang SS, Devesa SS, Hartge P, Weisenburger DD and Linet MS: Lymphoma incidence patterns by WHO subtype in the United States, 1992-2001. Blood 107: 265-276, 2006.

7. Watson L, Wyld P and Catovsky D: Disease burden of chronic lymphocytic leukaemia within the European Union. Eur J Haematol 81: 253-258, 2008.

8. Azuma K, Ifuku S, Osaki T, Okamoto Y and Minami S: Preparation and biomedical applications of chitin and chitosan nanofibers. J Biomed Nanotechnol 10: 2891-2920, 2014.

9. Azuma K, Osaki T, Minami S and Okamoto Y: Anticancer and anti-inflammatory properties of chitin and chitosan oligosaccharides. J Funct Biomater 6: 33-49, 2015.

10. Domard A: A perspective on 30 years research on chitin and chitosan. Carbohydr Polym 84: 696-703, 2011.

11. Aam BB, Heggset EB, Norberg AL, Sørlie M, Vårum KM and Eijsink VG: Production of chitooligosaccharides and their potential applications in medicine. Mar Drugs 8: 1482-1517, 2010.

12. Lee E, Kim H, Lee IH and Jon S: In vivo antitumor effects of chitosan-conjugated docetaxel after oral administration. J Control Release 140: 79-85, 2009.

13. Yuan WP, Liu B, Liu CH, Wang XJ, Zhang MS, Meng XM and Xia XK: Antioxidant activity of chito-oligosaccharides on pancreatic islet cells in streptozotocin-induced diabetes in rats. World J Gastroenterol 15: 1339-1345, 2009.

14. No HK, Park NY, Lee SH and Meyers SP: Antibacterial activity of chitosans and chitosan oligomers with different molecular weights. Int J Food Microbiol 74: 65-72, 2002.

15. Francesko A and Tzanov T: Chitin, chitosan and derivatives for wound healing and tissue engineering. Adv Biochem Eng Biotechnol 125: 1-27, 2011.

16. Yeh MY, Wu MF, Shang HS, Chang JB, Shih YL, Chen YL, Hung HF, Lu HF, Yeh C, Wood WG, et al: Effects of chitosan on xenograft models of melanoma in $\mathrm{C} 57 \mathrm{BL} / 6$ mice and hepatoma formation in SCID mice. Anticancer Res 33: 4867-4873, 2013.

17. Kim MS, Sung MJ, Seo SB, Yoo SJ, Lim WK and Kim HM: Water-soluble chitosan inhibits the production of pro-inflammatory cytokine in human astrocytoma cells activated by amyloid beta peptide and interleukin-1beta. Neurosci Lett 321: 105-109, 2002.

18. Jeong EJ, Choi M, Lee J, Rhim T and Lee KY: The spacer arm length in cell-penetrating peptides influences chitosan/siRNA nanoparticle delivery for pulmonary inflammation treatment. Nanoscale 7: 20095-20104, 2015.

19. Boyles MS, Kristl T, Andosch A, Zimmermann M, Tran N, Casals E, Himly M, Puntes V, Huber CG, Lütz-Meindl U and Duschl A: Chitosan functionalisation of gold nanoparticles encourages particle uptake and induces cytotoxicity and pro-inflammatory conditions in phagocytic cells, as well as enhancing particle interactions with serum components. J Nanobiotechnology 13: 84, 2015.

20. Yeh MY, Shih YL, Chung HY, Chou J, Lu HF, Liu CH, Liu JY, Huang WW, Peng SF, Wu LY and Chung JG: Chitosan promotes immune responses, ameliorates glutamic oxaloacetic transaminase and glutamic pyruvic transaminase, but enhances lactate dehydrogenase levels in normal mice in vivo. Exp Ther Med 11: 1300-1306, 2016.

21. Hung FM, Shang HS, Tang NY, Lin JJ, Lu KW, Lin JP, Ko YC, Yu CC, Wang HL, Liao JC, et al: Effects of diallyl trisulfide on induction of apoptotic death in murine leukemia WEHI-3 cells in vitro and alterations of the immune responses in normal and leukemic mice in vivo. Environ Toxicol 30: 1343-1353, 2015. 
22. Chang YC, Lai TY, Yu CS, Chen HY, Yang JS, Chueh FS, Lu CC, Chiang JH, Huang WW, Ma CY and Chung JG: Emodin induces apoptotic death in murine myelomonocytic leukemia WEHI-3 cells in vitro and enhances phagocytosis in leukemia mice in vivo. Evid Based Complement Alternat Med 2011: 523596, 2011.

23. Wang S, Zhu J and Liu Y: A novel anti-adhesion peptide ( $\beta 3)$ inhibits hepatocellular carcinoma activity in vitro and in vivo. Oncol Lett 12: 4744-4748, 2016.

24. Recommendations of the german society for clinical chemistry. Standardization of methods for the determination of enzyme activities in biological fluids. Z Klin Chem Klin Biochem 8: 658-660, 1970.

25. Nagamatsu Y, Yamamoto J, Fukuda A, Ohta M, Tsuda Y and Okada Y: Determination of leukocyte elastase concentration in plasma and serum by a simple method using a specific synthetic substrate. Haemostasis 21: 338-345, 1991.

26. Wei P, Ma P, Xu QS, Bai QH, Gu JG, Xi H, Du YG and Yu C: Chitosan oligosaccharides suppress production of nitric oxide in lipopolysaccharide-induced N9 murine microglial cells in vitro. Glycoconj J 29: 285-295, 2012.

27. Madhuprakash J, El Gueddari NE, Moerschbacher BM and Podile AR: Production of bioactive chitosan oligosaccharides using the hypertransglycosylating chitinase-D from Serratia proteamaculans. Bioresour Technol 198: 503-509, 2015

28. Liu B, Liu WS, Han BQ and Sun YY: Antidiabetic effects of chitooligosaccharides on pancreatic islet cells in streptozotocin-induced diabetic rats. World J Gastroenterol 13: 725-731, 2007.

29. Wu CC, Lin SY, Chen CT, Chang YP, Huang YS, Lii CK, Yu CC Hsieh SL and Chung JG: Differential blood lipid-lowering effects of alkylsulfonated chitosan of different molecular weights in Syrian hamsters in vivo. Mol Med Rep 5: 688-694, 2012.

30. Arpinati $\mathbf{M}$ and Curti A: Immunotherapy in acute myeloid leukemia. Immunotherapy 6: 95-106, 2014.

31. Kim KH, Kim TS, Lee JG, Park JK, Yang M, Kim JM, Jo EK and Yuk JM: Characterization of proinflammatory responses and innate signaling activation in macrophages infected with mycobacterium scrofulaceum. Immune Netw 14: 307-320, 2014.
32. Gordon S, Plüddemann A and Mukhopadhyay S: Sinusoidal immunity: Macrophages at the lymphohematopoietic interface. Cold Spring Harb Perspect Biol 7: a016378, 2015.

33. Gordon S and Taylor PR: Monocyte and macrophage heterogeneity. Nat Rev Immunol 5: 953-964, 2005.

34. Davies LC, Jenkins SJ, Allen JE and Taylor PR: Tissue-resident macrophages. Nat Immunol 14: 986-995, 2013.

35. Chou TC, Fu E and Shen EC: Chitosan inhibits prostaglandin E2 formation and cyclooxygenase-2 induction in lipopolysaccharide-treated RAW 264.7 macrophages. Biochem Biophys Res Commun 308: 403-407, 2003.

36. Yoon HJ, Moon ME, Park HS, Im SY and Kim YH: Chitosan oligosaccharide (COS) inhibits LPS-induced inflammatory effects in RAW 264.7 macrophage cells. Biochem Biophys Res Commun 358: 954-959, 2007.

37. Arancibia R, Maturana C, Silva D, Tobar N, Tapia C, Salazar JC, Martinez J and Smith PC: Effects of chitosan particles in periodontal pathogens and gingival fibroblasts. J Dent Res 92: 740-745, 2013.

38. Santoni A, Zingoni A, Cerboni $\mathrm{C}$ and Gismondi A: Natural killer (NK) cells from killers to regulators: Distinct features between peripheral blood and decidual NK cells. Am J Reprod Immunol 58: 280-288, 2007.

39. Yamashita T, Ohshima H, Asanuma T, Inukai N, Miyoshi I, Kasai N, Kon Y, Watanabe T, Sato F and Kuwabara M: The effects of alpha-phenyl-tert-butyl nitrone (PBN) on copper-induced rat fulminant hepatitis with jaundice. Free Radic Biol Med 21: 755-761, 1996. 